\title{
Methods of measuring retention of radio-isotopes in the knee and extra-articular spread in vivo
}

\author{
E. D. WILLIAMS \\ Department of Medical Physics, Hammersmith Hospital, London
}

The two radionuclides most commonly used for intra-articular therapy are ${ }^{198} \mathrm{Au}$ and ${ }^{90} \mathrm{Y}$. Both emit $\beta$-radiation, which is absorbed within a small distance from the site of emission in tissue. The decay of ${ }^{198} \mathrm{Au}$ is also accompanied by $\gamma$-radiation, which can be detected from outside the body using a scintillation detector. ${ }^{90} \mathrm{Y}$, however, has no $\gamma$-emission, but its presence can be detected from outside the body because Bremsstrahlung is produced when the $\beta$ radiation is absorbed in tissue. This radiation has a broad energy spectrum, with a peak at low energies. The intensity is much lower than that from the same radioactivity of ${ }^{198} \mathrm{Au}$, since only about 1 per cent. of the energy of the $\beta$-radiation produces Bremsstrahlung when absorbed in tissue. However, since relatively large amounts of radioactivity (several $\mathrm{mCi}$.) are usually administered, it is possible to detect this radiation and to measure the amount of radioactivity at a particular site in the body.

External counting may be performed using stationary scintillation detectors, a profile scanner, a gamma camera, or an area scanner (in order of decreasing sensitivity). Quantitative rather than qualitative methods of using these instruments are more likely to prove useful in comparing different regimes of treatment, and are necessary to estimate radiation dose.

\section{Methods}

The principal physical difference between measuring ${ }^{198} \mathrm{Au}$ and ${ }^{90} \mathrm{Y}$ in the body is due to the absence of $\gamma$-radiation from ${ }^{90} \mathrm{Y}$. With ${ }^{198} \mathrm{Au}$, the pulse height analyser can be set to include the photopeak, and there is little difficulty in discriminating against scattered radiation. With ${ }^{90} \mathrm{Y}$ it was found best for scanning to set the pulse height analyser window equivalent to the energy range $60-200 \mathrm{keV}$. Thus, only a portion of the spectrum of Bremsstrahlung was accepted, and scattered radiation could not be excluded. For all measurements with ${ }^{90} \mathrm{Y}$ a piece of aluminium $1 \mathrm{~mm}$. thick was placed in front of the detectors to absorb any $\beta$-radiation escaping from the patient.

Selection of the method of measurement is influenced by the site at which radioactivity is to be measured. One method referred to below is quantitative scanning, in which a dual detector scanner, which is normally used only to obtain an image of the distribution of radioactivity, is used to measure localized radioactivity. The total number of counts obtained while scanning an organ is related to the radioactivity in it, using calibration factors obtained by scanning water phantoms (Williams, Glass, Arnot, Goolden, and De Garreta, 1969).

\section{(a) Retention at site of injection}

Measurements of the retention of ${ }^{90} \mathrm{Y}$ injected into the knee for the treatment of persistent synovitis were made in a series of eleven patients (Gumpel, Williams, and Glass, 1973) by quantitative scanning. An assessment of the accuracy of this method of measurement was made by scanning shortly after the injection. The mean difference between the measured radioactivity and that expected (100 per cent. of the dose) in six cases was less than 3 per cent.

The use of a scanning method has the advantage of showing the distribution of radioactivity quantitatively. Thus, lateral view scans of the knee of a patient with a Baker's cyst showed that after 24 hours 51 per cent. of the radioactivity remaining in the knee was in the cyst, increasing to 57 per cent. at 5 days after injection.

Scanning is not necessarily the best method of measuring retention in the knee. In ten patients injected with ${ }^{90} \mathrm{Y}$, a comparison was made between measurements of retention taken over several days by scanning and by counting with two opposed stationary detectors. The detectors used were the 3 in. diam. $\times 2$ in. thick $\mathrm{NaI}(\mathrm{Tl})$ crystals on a scanner, which were positioned $20 \mathrm{~cm}$. above and below the knee. The focusing collimators were replaced by circular lead apertures. While a single detector alone gave results which were in poor agreement with the scan data, the summed output of two detectors was better, the retention differing by a mean of \pm 8 per cent. from that measured by scanning (Table I, overleaf). The much greater sensitivity of the stationary detectors enabled these measurements to be made in a very short time. This result should be equally applicable to measurements of ${ }^{198} \mathrm{Au}$. With large detectors without focusing collimators, however, the count rate from several millicuries of ${ }^{198} \mathrm{Au}$ would be very high and subject to coincidence losses. The count rate would therefore have to be reduced by, for example, shielding most of the detector or placing attenuating material in front of it.

For profile scanning, two opposed detectors are 
Table I Comparison of the use of a dual detector scanner and two opposed stationary detectors for measuring ${ }^{90} Y$ retention in the knee

Each value is the mean of a total of 31 measurements on ten patients

\begin{tabular}{|c|c|c|c|c|}
\hline Stationary detectors & $\begin{array}{l}\text { Upper } \\
(U)\end{array}$ & $\begin{array}{l}\text { Lower } \\
(L)\end{array}$ & $\begin{array}{l}\text { Geometric mean } \\
(\sqrt{ } U L)\end{array}$ & $\begin{array}{l}\text { Sum } \\
(U+L)\end{array}$ \\
\hline Difference from retention measured by scanning* (per cent.) & $\pm 16 \cdot 4$ & \pm 33.7 & $\pm 8 \cdot 5$ & $\pm 7 \cdot 8$ \\
\hline
\end{tabular}

* As a percentage of activity measured by scanning.

necessary to obtain quantitative results, because of changes in the distribution of radioactivity within the joint.

\section{(b) Uptake in the liver}

Stationary counters are unsuitable for measuring absolute uptake of radioactivity in the liver since this is a very large organ, and it would be difficult to obtain similar counting geometry, when using a phantom for comparison. However, a dual detector profile scanner or an area scanner would be suitable instruments.

\section{(c) Uptake in regional lymph nodes}

If a stationary detector is used to measure uptake in lymph nodes, the field of view of the detector should be broad enough to include all groups of nodes containing radioactivity. The depth of the nodes in tissue must be estimated for comparison with a suitable phantom or alternatively both anterior and posterior measurements can be made.

The advantage of area scanning for lymph node uptake is that the site of uptake can be positively

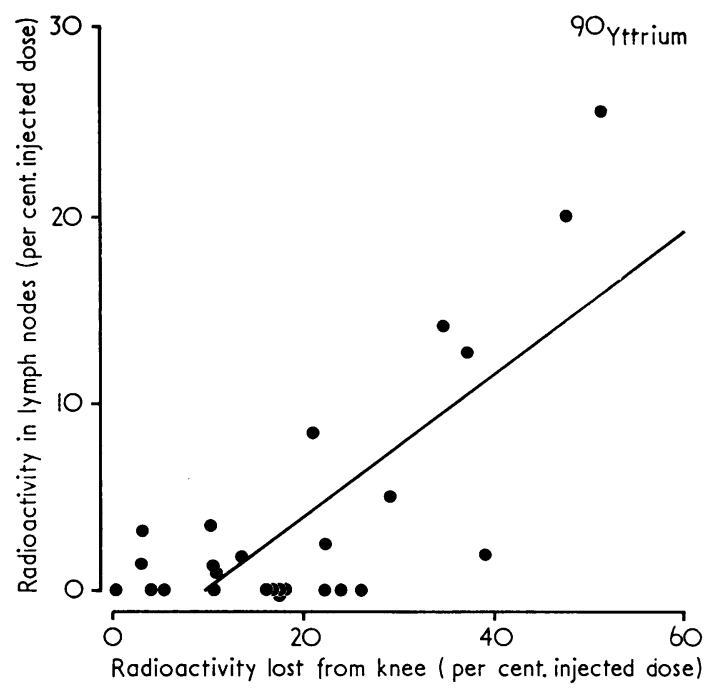

FIGURE Radioactivity measured in lymph nodes by quantitative scanning was related to that lost from the site of injection $(\mathrm{y}=0.38 \mathrm{x}-3.6 ; \mathrm{r}=0 \cdot 76)$, but accounted for less than half the loss identified with the lymph nodes, and corrections made to allow for radioactivity in adjacent tissues.

The parameter which it seems most relevant to measure in assessing different radiopharmaceuticals is their retention in the treated joint, because it is this radioactivity which will produce the desired therapeutic effects. In eleven patients whose knees were injected with ${ }^{90} \mathrm{Y}$, uptake in lymph nodes and loss from the knee were measured by scanning. Uptake in the lymph nodes was related to loss from the knee, but accounted for only about half this loss (Figure). This finding suggests that lymph node uptake is not a reliable guide to loss of radioactivity from the joint. It is simpler and more appropriate to measure the retention in the knee.

\section{Calculation of radiation dose}

In addition to assessing a method of treatment, measurements of retention in a joint can be used in estimating the radiation dose to that joint. ${ }^{90} \mathrm{Y}$ colloid is rapidly absorbed by synovial tissues (Webb, Lowe, and Bluestone, 1969; Prichard, Bridgman, and Bleehen, 1970). For the purposes of calculation, the colloid was assumed to be uniformly distributed over an area estimated from scans of the knee. The total area of synovial membrane was assumed to be approximately twice the sum of the anterior and lateral view projected areas of radioactivity on these scans, or four times the anterior view projected area if no lateral scan was performed. The membrane was assumed to be $1 \mathrm{~mm}$. thick, with ${ }^{90} \mathrm{Y}$ uniformly distributed on its surface. The radiation dose delivered at a depth of $1 \mathrm{~mm}$. was $270 \mathrm{r} \mu \mathrm{Ci}^{-1} \mathrm{~cm} .^{-2}$ (Jones, 1961). The effect of loss of ${ }^{90} \mathrm{Y}$ from the knee was expressed by calculating the ratio of the radiation dose delivered to the dose which would have been given had no loss occurred ('retention fraction'). Estimated radiation doses to the knee are shown in Table II. These estimates must be inaccurate because the true distribution of ${ }^{90} Y$ in each knee was unknown. However, since the radiation dose estimates vary by a factor of four from the highest to the lowest, it is clear that there will be a wide variation in the radiation doses to individual patients from the injection of the same radioactivity.

Radiation doses to the lymph nodes were also estimated from uptake measurements obtained by 
Table II Estimates of radiation dose to the synovial membrane of the knee from $5 \mathrm{mCi} .{ }^{90} \mathrm{Y}$

\begin{tabular}{|c|c|c|c|c|c|}
\hline \multirow[t]{2}{*}{ Patient no. } & \multirow[t]{2}{*}{ Knee } & \multirow[t]{2}{*}{$\begin{array}{l}\text { Retention } \\
\text { fraction }\end{array}$} & \multicolumn{2}{|c|}{$\begin{array}{l}\text { Area of distribution of }{ }^{90} Y \\
(\text { from scans })\left(\mathrm{cm}^{2}\right)\end{array}$} & \multirow{2}{*}{$\begin{array}{l}\text { Estimated radiation dose } \\
\text { at } 1 \mathrm{~mm} \text {. depth } \\
\left(\text { rad } \times 10^{3}\right)\end{array}$} \\
\hline & & & Anterior & Lateral & \\
\hline 1 & $\begin{array}{l}R^{(1)} \\
R^{(2)} \\
L^{(2)}\end{array}$ & $\begin{array}{l}0.65 \\
0 \cdot 81 \\
0 \cdot 87\end{array}$ & $\begin{array}{l}67 \\
73 \\
61\end{array}$ & $\begin{array}{l}\overline{52} \\
66\end{array}$ & $\begin{array}{l}3 \cdot 3 \\
2 \cdot 2 \\
6 \cdot 9\end{array}$ \\
\hline 2 & $\begin{array}{l}\mathbf{R} \\
\mathbf{L}\end{array}$ & $\begin{array}{l}0.82 \\
0.82\end{array}$ & $\begin{array}{l}70 \\
67\end{array}$ & 二 & $\begin{array}{l}3 \cdot 9 \\
4 \cdot 1\end{array}$ \\
\hline 3 & $\mathbf{L}$ & 0.87 & 40 & - & $7 \cdot 3$ \\
\hline 4 & $\overline{\mathbf{R}}$ & 0.66 & 89 & - & $2 \cdot 5$ \\
\hline 5 & $\mathbf{R}$ & 0.84 & 46 & 47 & $6 \cdot 1$ \\
\hline 6 & $\mathbf{R}$ & 0.81 & 85 & 110 & $2 \cdot 8$ \\
\hline 7 & $\mathbf{R}$ & 0.88 & 56 & 51 & $5 \cdot 6$ \\
\hline 8 & $\mathbf{L}$ & 0.92 & 41 & 44 & $7 \cdot 3$ \\
\hline 9 & $\mathbf{R}$ & 0.93 & 36 & 24 & $10 \cdot 4$ \\
\hline 10 & $\begin{array}{l}\mathbf{R} \\
\mathbf{L}\end{array}$ & $\begin{array}{l}0.94 \\
0.97\end{array}$ & $\begin{array}{l}31 \\
34\end{array}$ & $\begin{array}{l}58 \\
34\end{array}$ & $\begin{array}{l}7 \cdot 1 \\
9 \cdot 6\end{array}$ \\
\hline 11 & $\begin{array}{l}\mathbf{R} \\
\mathbf{L}\end{array}$ & $\begin{array}{l}0.90 \\
0.86\end{array}$ & $\begin{array}{l}56 \\
47 \\
\end{array}$ & $\begin{array}{l}40 \\
37\end{array}$ & $\begin{array}{l}6 \cdot 4 \\
7 \cdot 0\end{array}$ \\
\hline
\end{tabular}

(1) $2.5 \mathrm{mCi}$. injected

(2) $7.5 \mathrm{mCi}$. injected.

Table III Estimates of radiation dose to the lymph nodes from $5 \mathrm{mCi} .{ }^{90} \mathrm{Y}$ injected in the knee

\begin{tabular}{|c|c|c|}
\hline $\begin{array}{l}\text { Patient } \\
\text { no. }\end{array}$ & $\begin{array}{l}\text { Maximum uptake } \\
\text { observed in lymph nodes } \\
\text { (per cent. injected dose) }\end{array}$ & $\begin{array}{l}\text { Estimated lymph node } \\
\text { radiation dose } \\
(\text { weight } 10 \mathrm{~g} .) \\
\left(\mathrm{rad} \times 10^{3}\right)\end{array}$ \\
\hline $\begin{array}{l}1 \mathbf{R}^{\mathbf{( 1 )}} \\
\mathbf{R}^{(2)}\end{array}$ & $\begin{array}{l}25 \cdot 5 \\
14 \cdot 0 \\
5 \cdot 0\end{array}$ & $\begin{array}{l}12 \cdot 2 \\
3 \cdot 8 \\
3 \cdot 2\end{array}$ \\
\hline 3 & 1.5 & $1 \cdot 1$ \\
\hline 4 & 1.9 & 1.3 \\
\hline 6 & 2.4 & 1.6 \\
\hline 8 & 3.5 & $2 \cdot 3$ \\
\hline
\end{tabular}

scanning. The weight of these lymph nodes was assumed to be $10 \mathrm{~g}$., although there could be considerable variation in this figure (Seitzman, Wright, Halaby, and Freeman, 1963). Where uptake in lymph nodes was detected, the estimated radiation doses were typically several thousand rads (Table III). These estimated doses have been found to be related to lymphocyte chromosome aberrations (Stevenson, Bedford, and 11 others, 1973).

\section{Conclusion}

In assessing different radiopharmaceuticals or treatment regimes for intra-articular therapy, it is useful to know the fate of the radionuclide. The preferred nuclide is probably ${ }^{90} \mathrm{Y}$, since it emits only $\beta$-radiation, and the best method for measuring retention in the knee is by counting the Bremsstrahlung with two opposed stationary detectors. Uptake in lymph nodes and liver may be of secondary importance, but the site of uptake can be positively identified by scanning and the amount of uptake determined by using dual detector quantitative scanning techniques.

\section{Discussion}

MR. CRAWLEY We have built a hybrid scanner at the Clinical Research Centre. This consists of two line detectors, one above and one below the patient, who moves on a couch between them. Electronic equipment gives whole body pictures of the anterior and posterior views of the patient, an $x, y$ plotter gives a profile scan, and scalers can be switched in to give the total counts in any region of the body (Figs 1 and 2, overleaf).

We have used this instrument to measure leakage from the knees and to find where any isotope lost from the knees has been retained. Using a standard of ${ }^{90} \mathrm{Y}$ we can express our results in terms of the original dose. Further refinement of the electronic circuits is in hand and it should soon be possible to distinguish the two knees 
automatically. At the moment we separate the knees by wrapping each one in turn in a sheet of lead.

The results of our tests will be given in detail by Dr. Beer. Details of the hybrid scanner were given at the recent conference of radio-isotope scintigraphy at Monte Carlo (Crawley and Veall, 1973).
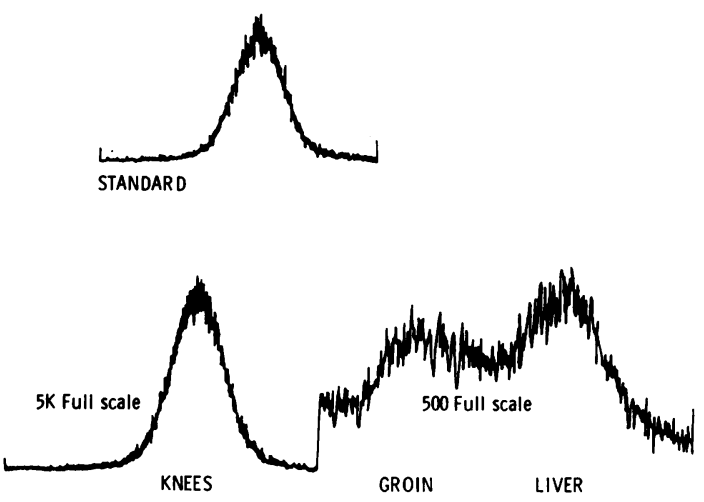

FIG. 1 Profile scan, showing some uptake in groin and liver. The sensitivity of the scanner was increased ten times in order to accentuate the groin and liver peaks.

FIG. 2 Whole body picture of same patient with anterior and posterior views side by side. There is more uptake in the left groin and less activity in the left knee

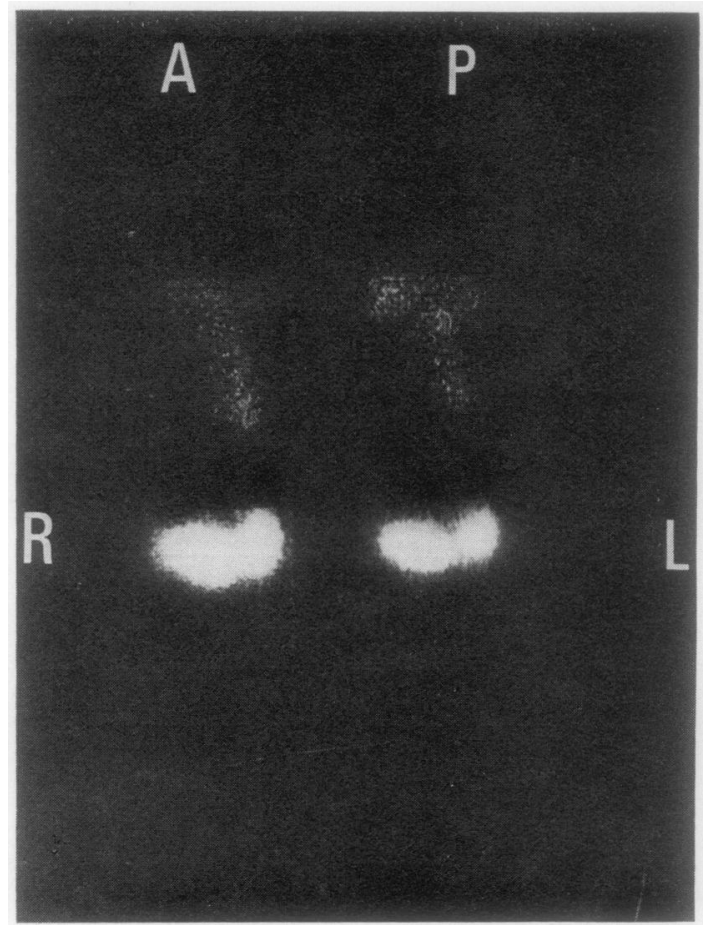

